\title{
Reconstruction of Severely Atrophic Mandible by Installing Dental Implants Using the Modified “Tent Pole" Technique: Case Report*
}

\author{
Rodrigo Tavares de Sá1,", Lincoln Lara Cardoso', Italo Cordeiro de Toledo², \\ Luis Gustavo Jaime Paiva², Guilherme Romano Scartezini², and Giovanni Gasperini3 \\ ${ }^{1}$ DDS, MS; Department of Oral and Maxillofacial Surgery, Clinical Hospital, Federal University of Goiás, Goias, Brazil \\ 2 DDS, MS; PhD; Department of Oral and Maxillofacial Surgery, Emergency Hospital of Aparecida de Goiânia, Goias, Brazil \\ ${ }^{3}$ DDS, MS; PhD; Department of Oral and Maxillofacial Surgery, Clinical Hospital, Federal University of Goiás, Goias, Brazil
}

AB OUT ARTICLE

Article history:

Paper received 21 August 2018

Accepted 05 September 2018

Available online 30 September 2018

Keywords:

Mandibular reconstruction

Dental implants

Atrophic mandible

"Tentpole" technique

"Tent pole" technique

Autogenous iliac crest graft

Platelet-rich plasma (PRP)

\begin{abstract}
A B S T R A C T
Summary.

Patients who use full dental prostheses for long periods of time usually experience bone resorption in the alveolar process and in keratinized mucosa. This can cause instability, low prosthetic retention, and subsequent loss of function. Treating a patient with a severely atrophic mandible is quite challenging due to the low bone height and thickness, potentially impairing rehabilitation, aesthetics, and functional recovery. Several techniques are used to reconstruct major vertical defects for the installation of dental implants. Among these is the "tent pole" technique, which features low morbidity and generally produces good results in the form of increased height of the alveolar ridge bone. Herein we describes a patient with a severely atrophic mandible, reconstructed using a plate and dental implants. We employed a modified "tent pole" technique using an autogenous graft of the iliac crest and without use of platelet-rich plasma concentrate. Our results indicate that the modified tent pole technique using the iliac crest graft, and without use of platelet-rich plasma, is a safe and effective method for achieving mandibular reconstruction while restoring function, aesthetics, and the patients' quality of life.
\end{abstract}

() 2018 OMF Publishing, LLC. This is an open access article under the CC BY licence

(http://creativecommons.org/licenses/by-nc/4.0/).

\section{Introduction}

In edentulous patients, prolonged use of removable total dental prostheses may cause reabsorption of the alveolar bone and consequent reduction of the keratinized mucosa. These processes can result in poor prosthetic retention and loss of function. Prosthetic maladjustment and constant trauma to the mucosa may produce pain as well as functional and aesthetic limitations that affect patients' quality of life $[1,2]$.

Treatment for a severely atrophic mandible is a major challenge for both the prosthodontist and the maxillofacial surgeon due to the minimal amount of alveolar ridge

\footnotetext{
* This manuscript has not been presented

* Corresponding author. Hospital das Clinicas, Universidade Federal de Goiás Av. $1^{\circ}$ Avenida, S/n, Setor Leste Universitário, Goiânia-Goiás, CEP: 74605-02012973, Brazil.

Phone: +556232698252

E-mail: rodrigo.tavares.sa@gmail.com (Dr.Rodrigo Tavares de Sá)

E-mails of the co-authors:

lincolnbuco@gmail.com (Lincoln Lara Cardoso)

italobuco@gmail.com (Italo Cordeiro de Toledo)

Ig.jp@hotmail.com (Luis Gustavo Jaime Paiva)

Ig.jp@hotmail.com (Luis Gustavo Jaime Paiva)

g_scartezini@yahoo.com.br (Guilherme Romano

http://dx.doi.org/10.23999/j.dtomp.2018.3.3
}

that is generally available. Several techniques have been described that can increase osseous volume, allowing the installation of dental implants [3], however, these techniques are also associated with complications such as extensive osseous reabsorption, pathological fractures, osseous graft failure, recurrent infections, fistulas, chronic pain, and sensory disorders [4].

In 2002, Marx et al [2] described the "tent pole" technique (synonym: tentpole technique) for tissue matrix expansion. This involves installation of 4 to 6 dental implants in patients whose mandibles have less than $6 \mathrm{~mm}$ of bone thickness, classified as Cawood-Howell type VI [1]. Using submandibular access, an autogenous iliac crest graft is used with platelet-rich plasma (PRP) concentrate and dental implants. The tent pole increase can reportedly increase bone height by as much as $10.2 \mathrm{~mm}$ [2].

PRP with bone grafts were successfully used in several studies in animals and humans [5-11]. Still other authors have reported successful use of the technique even without PRP [4].

Here in we report a clinical case involving reconstruction of a severely atrophic edentulous mandible through the fixation of a $2.4 \mathrm{~mm}$ reconstructive plate and use of a modified tent pole technique without use of PRP [12-16]. 


\section{Clinical Case Report}

A 71-year-old male patient, diagnosed with leukoderma, presented with complaints of impaired mastication, instability, and an inability to use his lower removable total prosthesis. The patient did not present with any systemic comorbidities. Clinical examination revealed edentulous arches, an atrophic mandible, a small amount of keratinized mucosa, and chronic oral mucosa trauma.

Panoramic jaw radiography and cone beam computed tomography revealed low mandibular bone availability, designated class $\mathrm{V}$ according to the classification system proposed by Cawood and Howell [1]. This rendered the patient's mandible unsuitable for rehabilitation using only integrated bone dental implants (Fig 1).

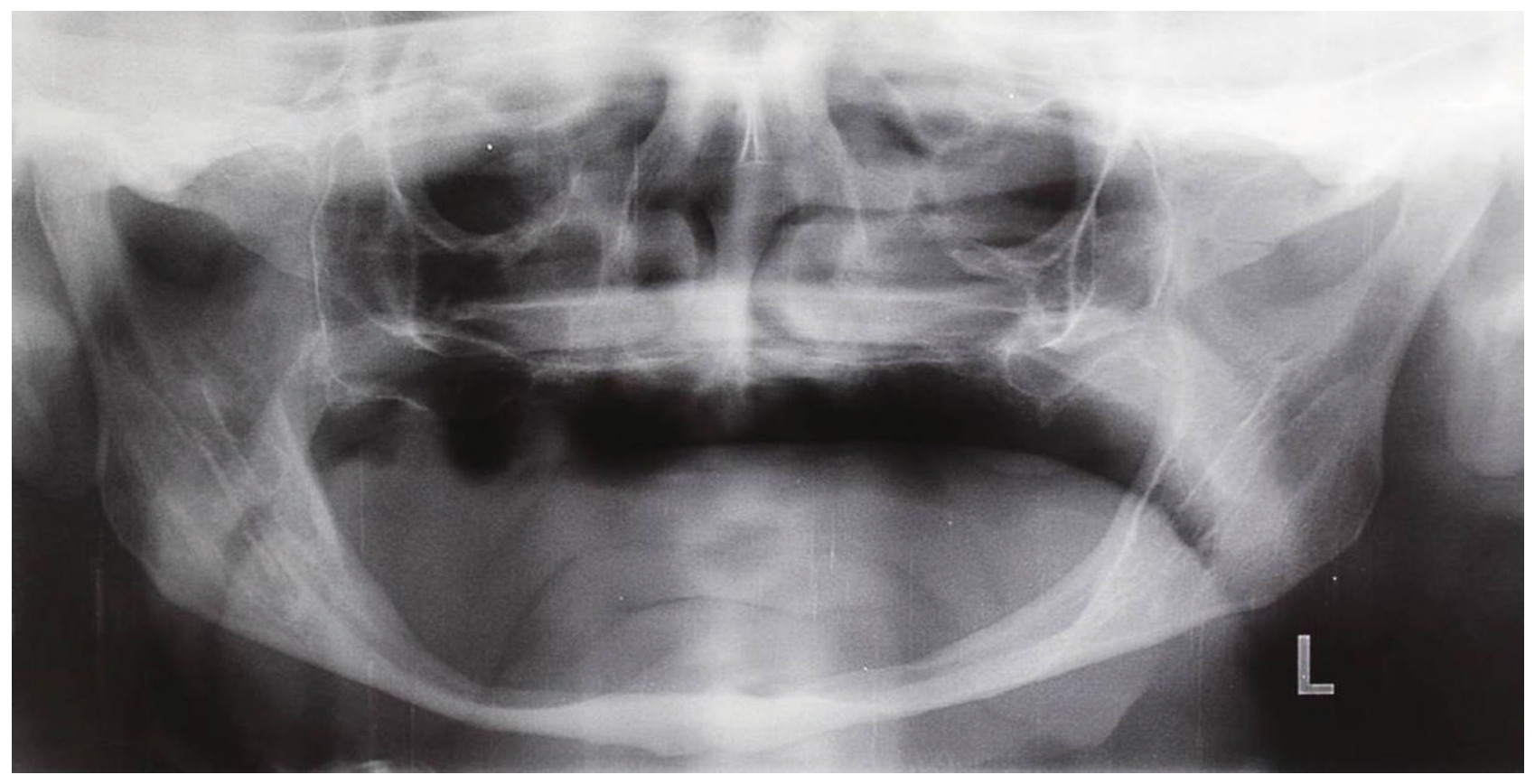

FIGURE 1. Panoramic preoperative radiograph; note the severe bone reabsorption, classified as type VI, according to Cawood and Howell [1].

The procedure was performed under general anesthesia. Marx et al [2], protocol involving submandibular access with exposure of the mandible and installation of 4 to 6 implants in the anterior region of mandible, between the two mental foramens.

One $2.4 \mathrm{~mm}$ reconstructive plate (OsteoMed, Addison, Texas, USA) was installed, followed by mandibular body to body to support the mandibular masticatory load. Two $11 \mathrm{~mm}$ implants (Neodent, Curitiba, Paraná, Brazil), with $3.0 \mathrm{~mm}$ platforms, were centrally mounted followed by another two (Neodent, Curitiba, Paraná, Brazil), more distal $13 \mathrm{~mm}$ implants with $3.3 \mathrm{~mm}$ platforms (Fig 2A). We then removed the right anterior iliac crest graft.

A bone crusher was used to form small bone particles to facilitate adaptation fitting strategically around each dental implant. Both particulate graft and dental implants were covered with two collagen membranes (Geistlich Bio-Gide, Switzerland), the platelet-rich plasma was not use (Fig 2B). Thus surgical approach was synthesized with 4-0 vycril sutures for internal layers and 5-0 nylon sutures for skin. During the period of implant osseointegration and bone graft incorporation, the patient was advised not to use his lower total prosthesis and only consume soft consistency food throughout the postoperative period.

The osseointegration and bone graft incorporation processes took seven months to complete. Following reopening of the implants under local anesthesia, an alveolar crest incision was made to the mental foramen, the mucoperiosteum was then detached and the implant lid screws were removed without any difficulties. Transmucosal cicatrizers were finally installed and the patient was referred for rehabilitation with prosthesis under the implant. At the time of this report, the patient had experienced no adverse effects over the 14 month postoperative period (Fig 3).

\section{Discussion}

Although the last few decades have seen great advances in dentistry, the rehabilitation of atrophic mandibles is quite delicate, requiring careful manipulation of remaining tissues in order to improve hard tissue availability. The autogenous bone graft is considered a gold standard technique and holds the advantage of increasing mandibular bone volume, establishing a better relationship between the maxilla and mandible, improving residual alveolar ridge shape, and producing great functional and aesthetic gains following prosthetic treatment $[4,17]$. 

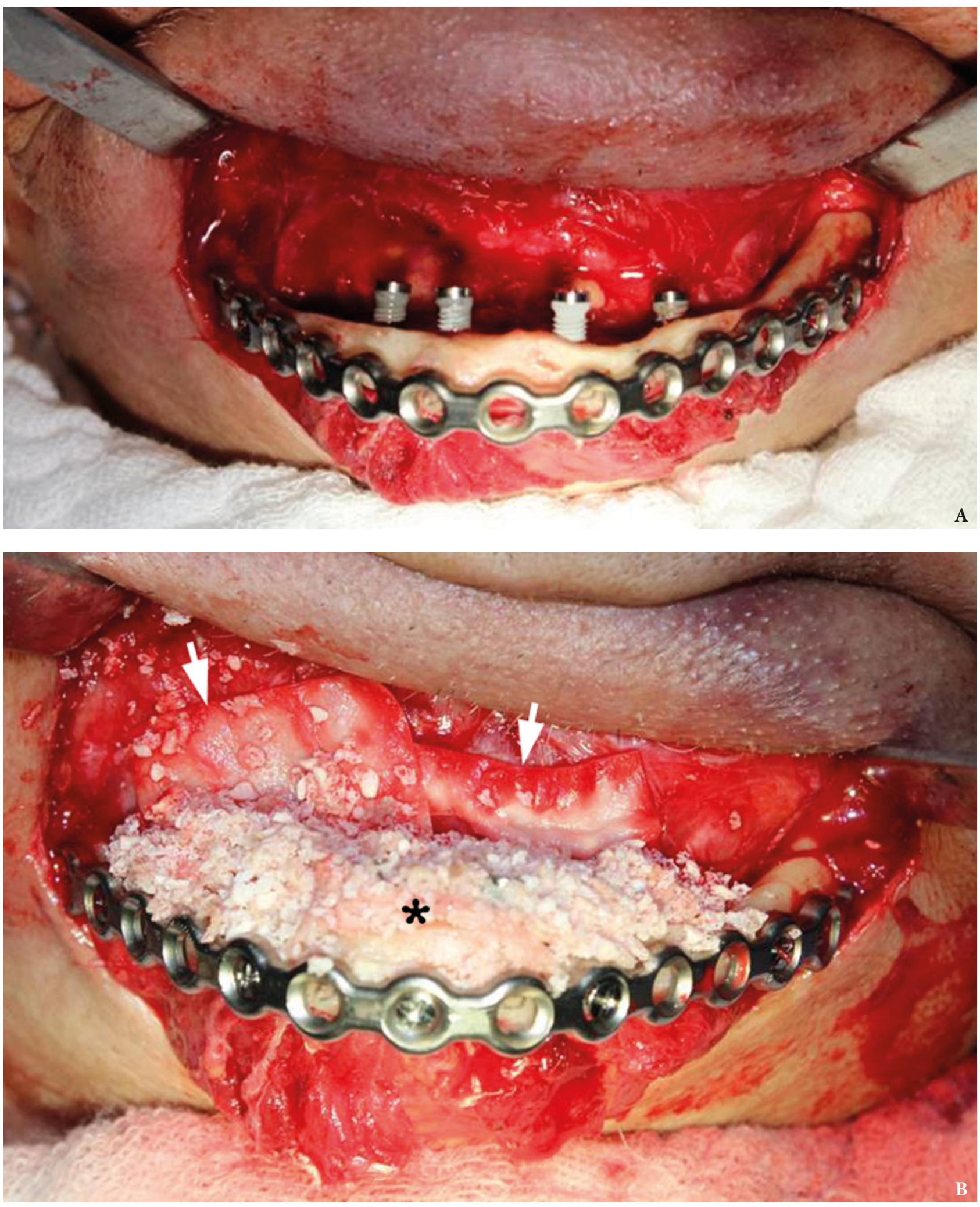

FIGURE 2. A - a $2.4 \mathrm{~mm}$ reconstruction plate was installed to the mandibular body, followed by installation of two central implants: an $11 \mathrm{~mm}$ implant with $3.0 \mathrm{~mm}$ platforms and two distal $13 \mathrm{~mm}$ implants with $3.3 \mathrm{~mm}$ platforms. B - Adaptation of an autogenous graft (asterisk) of the anterior iliac crest, with two collagen membranes (arrows) covering the graft. 


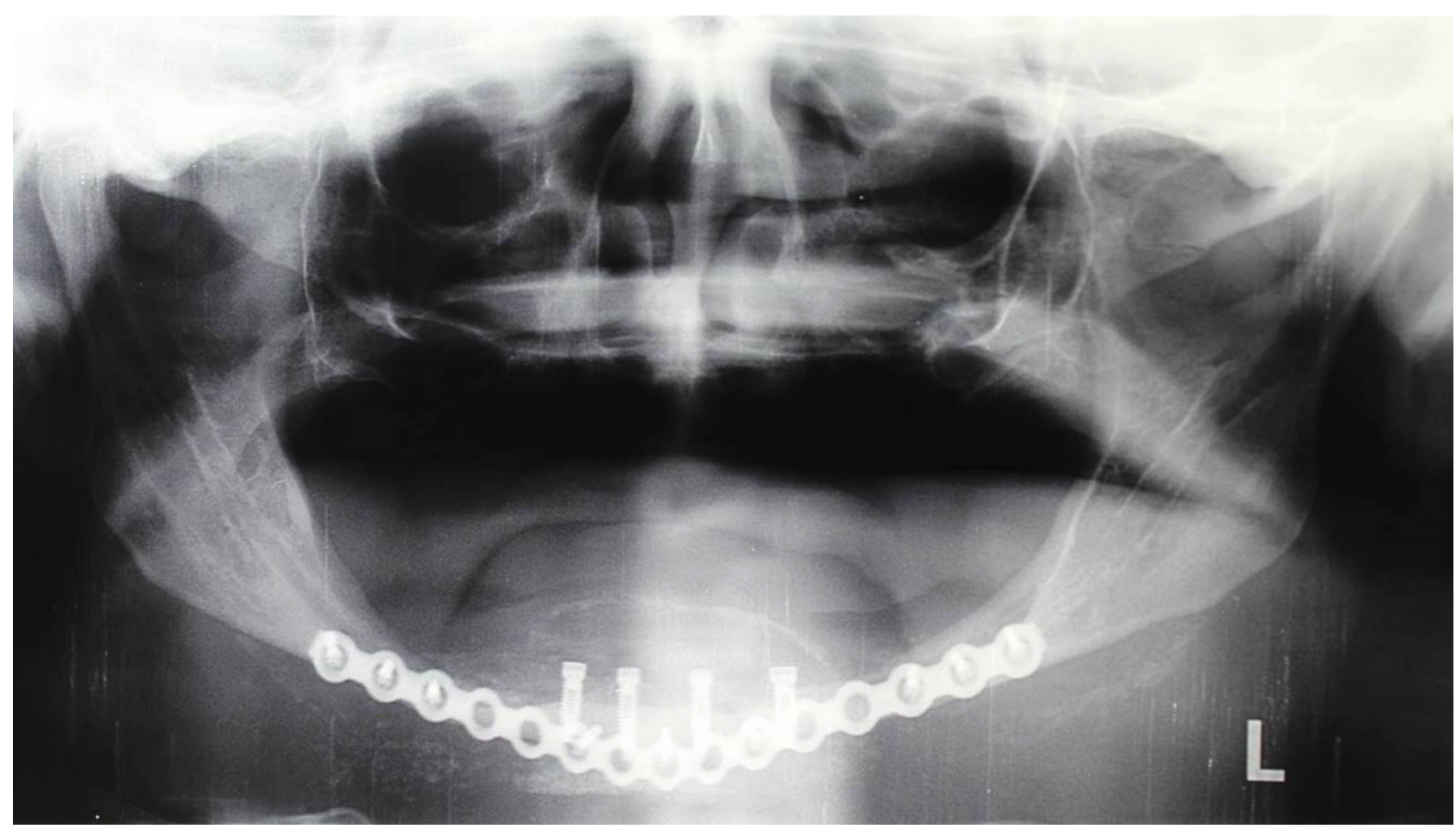

FIGURE 3. A panoramic radiograph at 1 year post fixation of the prosthesis using implants; note the bone gain (arrow) in the residual alveolar ridge.

The tent pole technique uses an autogenous iliac crest graft, followed by immediate installation of dental implants. This promotes greater hard tissue availability and soft tissue gains, produces efficient surgical results, and is associated with minimal morbidity [2].

The advantages of this procedure are stable height gains from osseous tissue, a lower risk of mandible fracture, and a successful prosthetic retention. Postoperative infections, mental nerve paresthesias, donor site deformities, and transoperative mandible fractures are complications associated with this procedure. ${ }^{5}$

Ellis and Prince [18] and Eyrich et al [20] reported that installation of a rigid fixation plate associated with a bone graft and followed by the immediate installation of dental implants produced more stable results, compared to the patients who only received bone grafts. This technique may help prevent mandibular fractures from occurring during the intraoperative period, especially when the mandible is less than $10 \mathrm{~mm}$ in height and therefore classified as severely atrophic $[1,5]$.

Marx et al [2] described installation of 4 to 6 implants which were covered with an iliac crest graft and PRP; however, Korpi et al [4] described a series of 22 patients successfully treated with iliac crest grafts and without PRP. Hence, questions surrounding the use of PRP as a component of this protocol remain unresolved.

The tent pole technique is a safe and effective alternative method for reconstruction of severely atrophic mandibles, even without the addition of PRP. This method can help solve functional and aesthetic complaints and improve the patient's quality of life. Because the use of PRP remains uncertain in the literature, additional double blind and randomized clinical trials are needed to define the role of PRP in these reconstructions.

\section{Conflict of Interest}

The authors declare no conflict of interest.

\section{Role of the Authors and Co-authors}

Rodrigo Tavares de Sá (concept and design of the paper and writing)

Lincoln Lara Cardoso (material collection and writing) Italo Cordeiro de Toledo (material collection and writing) Luis Gustavo Jaime Paiva (material collection and writing) Guilherme Romano Scartezini (material collection and writing)

Giovanni Gasperini (material collection and editing)

\section{Ethical Approval}

None.

\section{Term of Consent}

Written patient consent was obtained from parents to publish the clinical photographs.

\section{Fundings}

No funding was received for this study 


\section{Acknowledgments}

None.

\section{References}

1. Cawood JI, Howell RA. A classification of the edentulous jaws. Int J Oral Maxillofac Surg 1988;17:232-6.

2. Marx RE, Shellenberger T, Wimsatt J, Correa P. Severely resorbed mandible: predictable reconstruction with soft tissue matrix expansion (tent pole) grafts. J Oral Maxillofac Surg 2002;60:878-88.

3. Bell RB, Blakey GH, White RP, Hillebrand DG, Molina A. Staged reconstruction of the severely atrophic mandible with autogenous bone graft and endosteal implants. J Oral Maxillofac Surg 2002;60(10):1135-41.

4. Korpi JT, Kainulainen VT, Sándor GK, Oikarinen KS Long-term follow-up of severely resorbed mandibles reconstructed using tent pole technique without plateletrich plasma. J Oral Maxillofac Surg 2012;70:2543-8. https:// doi.org/10.1016/j.joms.2012.07.027.

5. Marx RE, Carlson ER, Eichstaedt RM, Schimmele SR, Strauss JE, Georgeff KR. Platelet-rich plasma: growth factor enhancement for bone grafts. Oral Surg Oral Med Oral Pathol Oral Radiol Endod 1998;85(6):638-46.

6. Merkx MA, Fennis JP, Verhagen CM. Reconstruction of the mandible using preshaped $2.3 \mathrm{~mm}$ titanium plates, autogenous particulate cortico-cancellous bone grafts and platelet rich plasma: a report on eight patients. Int J Oral Maxillofac Surg 2004;33:733-9. https://doi.org/10.1016/j. ijom.2004.06.003.

7. Mooren RE, Merkx MA, Kessler PA, Jansen JA, Stoelinga PJ. Reconstruction of the mandible using preshaped 2.3$\mathrm{mm}$ titanium plates, autogenous cortical bone plates, particulate cancellous bone, and plateletrich plasma: a retrospective analysis of 20 patients. J Oral Maxillofac Surg 2010;68(10):2459-67. https://doi.org/10.1016/j. joms.2009.12.006.

8. Schlegel KA, Kloss FR, Kessler P, Schultze-Mosgau S, Nkenke E, Wiltfang J. Bone conditioning to enhance implant osseointegration: an experimental study in pigs. Int J Oral Maxillofac Implants 2003;18(4):505- 11.

9. Simon EN, Merkx MA, Shubi FM, Kalyanyama BM,
Stoelinga PJ. Reconstruction of the mandible after ablative surgery for the treatment of aggressive, benign odontogenic tumours in Tanzania: a preliminary study. Int J Oral Maxillofac Surg 2006;35(5):421-6. https://doi. org/10.1016/j.ijom.2005.10.009.

10. Thorn JJ, Sørensen H, Weis-Fogh U. Andersen M. Autologous fibrin glue with growth factors in reconstructive maxillofacial surgery. Int J Oral Maxillofac Surg 2004;33(1):95-100. https:// doi.org/10.1054/ijom.2003.0461.

11. Zechner W, Tangl S, Tepper G, Fürst G, Bernhart T, Haas R, Mailath G, Watzek G. Influence of platelet-rich plasma on osseous healing of dental implants: a histologic an histomorphometric study in minipigs. Int J Oral Maxillofac Implants 2003;18(1):15-22.

12. Aghaloo TL, Moy PK, Freymiller EG. Investigation of platelet-rich plasma in rabbit cranial defects: a pilot study. $J$ Oral Maxillofac Surg 2002;60(10):1176-81.

13. Gerard D, Carlson ER, Gotcher JE, Jacobs M. Effects of platelet-rich plasma on the healing of autologous bone grafted mandibular defects in dogs. J Oral Maxillofac Surg 2006;64(3):443-51. https://doi.org/10.1016/j. joms.2005.11.016.

14. Jakse N, Tangl S, Gilli R, Berghold A, Lorenzoni M, Eskici A, Haas R, Pertl C. Influence of PRP on autogenous sinus grafts: an experimental study on sheep. Clin Oral Implants Res 2003;14(5):578-83.

15. Schlegel KA, Donath K, Rupprecht S. Falk S, Zimmermann R, Felszeghy E, Wiltfang J. De novo bone formation using bovine collagen and platelet-rich plasma. Biomaterials 2004;25(23):5387-93.

16. Wiltfang J, Kloss FR, Kessler P, Nkenke E, Schultze-Mosgau S, Zimmermann R, Schlegel KA. Effects of platelet-rich plasma on bone healing in combination with autogenous bone and bone substitutes in critical-size defects. Clin Oral Implants Res 2004;15(2):187-93.

17. Peterson LJ. Augmentation of the mandibular residual ridge by a modified visor osteotomy. J Oral Maxillofac Surg 1983;41:332-8.

18. Ellis E 3rd, Price C. Treatment protocol for fractures of the atrophic mandible. J Oral Maxillofac Surg 2008;66(3):42135. https://doi.org/10.1016/j.joms.2007.08.042.

19. Eyrich GK, Grätz KW, Sailer HF. Surgical treatment of fractures of the edentulous mandible. J Oral Maxillofac Surg 1997;55(10):1081-7. 